\title{
Gaming Spatial Skill Development: Building STEM Pathways with the Use of the Minecraft Gaming Platform
}

\author{
Dr. Bryce E. Hughes, Montana State University - Bozeman
}

Bryce E. Hughes is an Assistant Professor in Adult and Higher Education at Montana State University, and holds a Ph.D. in Higher Education and Organizational Change from the University of California, Los Angeles, as well as an M.A. in Student Development Administration from Seattle University and a B.S. in General Engineering from Gonzaga University. His research interests include teaching and learning in engineering, STEM education policy, and diversity and equity in STEM.

\section{Dr. SHANNON D WILLOUGHBY WILLOUGHBY \\ Dr. Brock J. LaMeres P.E., Montana State University - Bozeman}

Dr. Brock J. LaMeres is a Professor in the Department of Electrical \& Computer Engineering at Montana State University (MSU) and the Director of the Montana Engineering Education Research Center (MEERC). LaMeres is also the Boeing Professor at MSU where he is responsible for initiatives to improve the professional skills of engineering graduates. LaMeres teaches and conducts research in the area of computer engineering. LaMeres is currently studying the effectiveness of online delivery of engineering content with emphasis on how the material can be modified to provide a personalized learning experience. LaMeres is also researching strategies to improve student engagement and how they can be used to improve diversity within engineering. LaMeres received his Ph.D. from the University of Colorado, Boulder. He has published over 90 manuscripts and 5 textbooks in the area of digital systems and engineering education. LaMeres has also been granted 13 US patents in the area of digital signal propagation. LaMeres is a member of ASEE, a Senior Member of IEEE, and a registered Professional Engineer in the States of Montana and Colorado. Prior to joining the MSU faculty, LaMeres worked as an R\&D engineer for Agilent Technologies in Colorado Springs, $\mathrm{CO}$ where he designed electronic test equipment.

Barrett Frank, Montana State University

Mrs. Elaine Marie Westbrook, Montana State University

Elaine Westbrook received a B.S. in Chemistry from Kennesaw State University in 1993. After a decade in industry, she turned her attention to education and taught secondary science for the following decade. In 2014, she received a Masters in Science Education from Montana State University. She is currently a doctoral student in the Education department at Montana State and researches gender differences of informal STEM education in rural areas.

\section{Dr. Nick Lux Lux, Montana State University}

Dr. Nicholas Lux has is an Associate Professor of Curriculum and Instruction in MSU's Department of Education. His teaching and research interests are in the area of educational technology. He has worked in the fields of K-12 and higher education for 18 years, and currently teaches in the Montana State University Teacher Education Program. He has experience in educational technology theory and practice in K-12 contexts and teacher education, with a focus on STEM teaching and learning, technology integration, online course design and delivery, program evaluation, and assessment. Dr. Lux's current research agenda is STEM teaching and learning in K-12 contexts, technology integration in teacher preparation and K-12 contexts, educational gaming design and integration, and new technologies for teaching and learning. 
Gaming Spatial Skill Development: Building STEM Pathways with the Use of the Minecraft Gaming Platform

(Work in Progress) 


\section{Introduction}

The ability to make spatial judgments and visualize objects in space has been found to be an indicator of students' future achievement in STEM [1-3]. Moreover, spatial intelligence has also been shown to be one of the only cognitive areas in which boys outperform girls, and these differences tend to emerge most often in the middle school years [4]. There are many theories to explain how adolescents develop spatial skills, but research indicates that one promising approach is engaging in a 3D environment [5-8]. Therefore, better understanding how best to build K-12 learners' spatial skills within a 3D gaming environment in an effort to improve success on pathways into STEM seemed a prudent direction for inquiry.

\section{The study}

In response to this gap in better understanding how 3D tools might be used to support spatial skill development in elementary and middle school learners, our research team hypothesized that a 3D gaming environment like Minecraft could provide the platform needed to promote the development of those spatial skills. We also hypothesized that we could leverage the popularity of the Minecraft game to build student interest in the activities that might be used to build those spatial skills. To do so, our team delivered a series of summer camps in 2018 and 2019 at which participants engaged in Minecraft-based activities that were designed to target two specific spatial skills: mental rotation and 2D-to-3D transformation. Findings from the first summer camp in 2018 have been previously shared. Consequently, the focus of this particular study is on findings from the second camp delivered in summer 2019. However, a quick review of findings from 2018 are shared below as they are critical in understanding how the researchers responded to the results and shifted the design of the intervention.

\section{Summer camp 2018}

For the first summer camp offered in 2018, the research team constructed two pilot modules to support the development of mental rotation and 2D to 3D transformation skills. This intervention was completed in the Minecraft environment, but was primarily designed in a tutorial-type or drill-and-practice fashion. Despite efforts to recruit an even gender distribution, demographic data collected from summer camp 2018 participants $(n=27)$ indicate that $74 \%(n=20)$ of participants identified male, and 26\% $(n=7)$ identified as female. Findings from the first summer camp suggest that learners' mental rotation skills did increase, but no growth was found in students' 2D-to-3D transformation skills. A paired-samples t-test was used to investigate spatial skill growth across all learners between the pre-test and post-test. Data analysis indicates that, across all learners, participants scored higher on the mental rotation post-test than on the pre-test, with a statistically significant increase of 1.0625 points on the 15 -item instrument (95\% CI, 1.6114 to -.5135$) \mathrm{km}, \mathrm{t}(31)=-3.9473, \mathrm{p}<.05$. Effect size was calculated, and the Cohen's $d$ was approximately .59, suggesting a medium effect of the treatment. Conversely, data analysis of the 2D-to-3D transformation measurement indicates students did score higher on the post-test than on the pre-test, but the difference was not statistically significant $(0.40625 ; 95 \% \mathrm{CI},-.9391$ to $.1266 \mathrm{~km}, \mathrm{t}(31)=-1.5549, \mathrm{p}=.1301)$. Interestingly, when isolated for gender, no significant differences were found between males and females. In summary, data analysis from the first summer camp in 2018 indicates that students scored significantly higher on the mental rotation 
post-test, but not on the 2D-to-3D transformation post-test. Qualitative data were also collected from summer camp 2018. Learners reported that a more engaging structure was needed for the spatial skills activities. Teacher consultants corroborated these findings, and the team set out to build a more engaging intervention for the second summer camp in 2019.

\section{Summer camp 2019}

As indicated, the study presented in this paper is specific to the second summer camp offered in 2019. In response to findings from the qualitative data from the first summer camp in 2018 , the research team reinvented the intervention in an effort to make the activities more engaging for learners and less drill-and-practice oriented. Consequently, the research team authored a fantasyworld storyline to drive the spatial skill activities for the second camp in 2019. Participants in this camp $(n=28)$ were given a narrative that guided them to work together within Minecraft to complete a series of puzzles. The goal of this storyline was to solve the puzzles, in this case spatial skill activities, in order to obtain artifacts and maps needed to save the world from an "invading zombie horde".

Demographic data from 2019 summer camp participants $(n=28)$ indicates that $50 \%(n=14)$ of participants identified male, and 50\% $(n=14)$ identified as female. This is important to note as the team focused efforts on female recruitment for the second camp in 2019 after observing that camp participants' genders in 2018 were not evenly distributed. One student had attended the previous summer 2018 summer camp. Summer camp 2019 participants shared what grade they were entering in the Fall of 2019 , and the majority $(36 \%, n=10)$ were entering $4^{\text {th }}$ grade, whereas $29 \%(n=8)$ were entering $5^{\text {th }}$ grade, $14 \%(n=4)$ were entering $6^{\text {th }}$ grade, and $21 \%(n=6)$ were entering $7^{\text {th }}$ grade. Participants were also asked about their experience playing Minecraft was well as their access to games at home. Data suggests that $43 \%(n=12)$ were relatively novice Minecraft players with little to no experience playing the game, $43 \%(n=12)$ of participants had some experience with Minecraft, and only a small portion of the participants had considerable Minecraft experience $(14 \%, n=4)$. No participants indicated that they were "experts" at Minecraft. The majority of participants $(56 \%, n=16)$ shared that they either had "a lot of access" to technology gaming consoles or even owned their own console or computer, and $43 \%(n=12)$ reported that they had some or little to no access to technology or gaming consoles at home.

\section{Preliminary findings}

Pre- and post-tests were administered at each camp to better understand the possible influence of the Minecraft-based activities on learners' spatial skills. As shared earlier, findings from summer camp 2018, where the game was structured more like a tutorial/drill-and-practice game, suggest that learners did increase their mental rotation skills. Conversely, preliminary results from summer camp 2019 data suggest that, although the new storyline approach was more engaging for learners, no spatial skill growth was detected.

Since finding that students' mean scores on the rotation and 2D-to-3D transformation tests did not significantly change from pre-test to post-test, the research team was interested in better understanding other variables related to spatial skills. As a result, data were also collected and analyzed related to duration of test completion and students' confidence in their responses. Test 
duration was measured in seconds, and for each question, students reported on a 3-point scale their degree of confidence in their response to the question, ranging from "very confident" (3) to "not confident" (1). Early results indicate that students were not significantly more confident in their ability to solve spatial skill puzzles at the end of the camp. However, preliminary results do suggest that participants were able to complete both the rotation and the 2D-to-3D transformation test quicker at the end of summer camp 2019. More specifically, participants completed the $2 \mathrm{D}$-to-3D test quicker on the post-test $(370.7 \pm 104.8)$ than on the pre-test (664.2 \pm 278.0$)$, which indicates a statistically significant increase in speed of 356.5 seconds, or 5.94 minutes faster (95\% CI, 192.1054 to 394.8456) seconds, $\mathrm{t}(24)=5.9750, \mathrm{p}<.05, \mathrm{~d}=1.39$. And participants completed the rotation test quicker on the post-test $(393 . \pm 175.4)$ than on the pre-test $(653.7 \pm 235.2)$ for a statistically significant increase in speed of 260.3 seconds, or 4.34 minutes (95\% CI, 173.7806 to 346.9601) seconds, $\mathrm{t}(26)=6.1809, \mathrm{p}<.05, \mathrm{~d}=1.26$. In summary, despite no conclusive findings indicating the intervention influenced a growth from pre-test to post-test on students' spatial skills, results do suggest that participants were able to solve spatial problems more swiftly.

\section{Preliminary conclusions \& implications}

Further research is needed to understand why significant spatial skill growth was found in Summer 2018, where the students reported the activities as less engaging, yet no spatial skill growth was found in summer 2019, where students reported high engagement from the storylinebased intervention. Further, results from the two camps will be used to continue to adjust the spatial skills activities for a summer camp to be delivered in 2020. Full findings will be included in the final poster.

\section{Funding}

This project is funded by the National Science Foundation under Award XXX- XXXXXX. Any opinions, findings, and conclusions or recommendations expressed in this material are those of the authors and do not necessarily reflect the views of the National Science Foundation.

\section{References}

[1] N. Veurink and A. Hamlin, "Spatial Visualization Skills: Impact on Confidence and Success in an Engineering Curriculum," presented at the 2011 ASEE Annual Conference \& Exposition, Vancouver, BC, 2011. [Online]. Available: https://peer.asee.org/18591.

[2] E. Towle, J. Mann, B. Kinsey, E. J. O. Brien, C. F. Bauer, and R. Champoux, "Assessing the self efficacy and spatial ability of engineering students from multiple disciplines," in Proceedings Frontiers in Education 35th Annual Conference, 19-22 Oct. 2005 2005, pp. S2C-15, doi: 10.1109/FIE.2005.1612216.

[3] S. A. Sorby, "Educational Research in Developing 3-D Spatial Skills for Engineering Students," International Journal of Science Education, vol. 31, no. 3, pp. 459-480, 2009, doi: 10.1080/09500690802595839.

[4] M.-T. Wang and J. Degol, "Motivational Pathways to STEM Career Choices: Using Expectancy-Value Perspective to Understand Individual and Gender Differences in 
STEM Fields," Developmental review : DR, vol. 33, no. 4, p. 10.1016/j.dr.2013.08.001, 09/13 2013, doi: 10.1016/j.dr.2013.08.001.

[5] R. H. McKim, Experiences in visual thinking. Boston, MA: PWS Publishers, 1980.

[6] D. H. Bowers, \& Evans, D.L, "The role of visualization in engineering design," in NSF Symposium on Modernization of the Engineering Design Graphics Curriculum, Austin, TX, 1990, pp. 89-94.

[7] B. W. Field, "A course in spatial visualization," in 6th International Conference on Engineering Design Graphics and Descriptive Geometry, Tokyo, 1994, pp. 257-261.

[8] S. A. Sorby, \& Gorska, R., "The effect of various courses and teaching methods on the improvement of spatial ability," in 8th International Conference on Engineering Design Graphics and Descriptive Geometry, Austin, TX, 1998. 